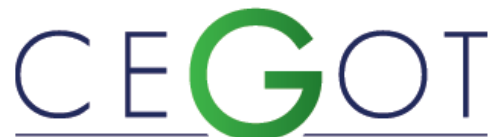

Centro de Estudos de Geografia e Ordenamento do Território

\section{ESPINDOLA JUNIOR, GUILHERME}

Universidade Estadual de Mato Grosso do Sul. Curso de Geografia, Laboratório de Geoprocessamento - Lageo

79115-898, Campo Grande, Mato Grosso do Sul, Brasil, Av. Dom Antonio Barbosa (MS080), 4155

guilhermeespindolajunior@gmail.com

\section{BAZANA BARBOSA, EDWALDO}

Universidade Estadual de Mato Grosso do Sul. Curso de Geografia, Laboratório de Geoprocessamento - Lageo

79115-898, Campo Grande, Mato Grosso do Sul, Brasil, Av. Dom Antonio Barbosa (MS080), 4155

bazana@uems.br

\title{
Análise paramétrica e uso da terra e cobertura vegetal da bacia hidrográfica do Córrego Ceroula-ms
}

Parametric analysis and land use and vegetation cover of the Ceroula-ms stream hydrographic basin

Referência: Espindola Junior, Guilherme; Barbosa, Edwaldo (2020). Análise paramétrica e uso da terra e cobertura vegetal da bacia hidrográfica do Córrego Ceroula-ms. Revista de Geografia e Ordenamento do Território (GOT), n.o 19 (junho). Centro de Estudos de Geografia e Ordenamento do Território, p. 218-234, dx.doi.org/10.17127/got/2020.19.009

\section{RESUMO}

A bacia hidrográfica é a principal unidade fisiográfica do terreno, considerada como a área ideal para o planejamento e gestão dos recursos naturais e dos processos produtivos. Este trabalho tem como objetivo analisar a parametria do terreno e o uso da terra e a cobertura vegetal da Bacia Hidrográfica do Córrego Ceroula (BHCC). A metodologia pautou-se na utilização de produtos de sensoriamento remoto que permitiram as análises de terreno e de uso da terra e cobertura vegetal em softwares de um SIG. As formas do relevo e a dinâmica natural contribuíram para a configuração do uso da terra e cobertura vegetal que se consolidam até os dias atuais, houve um leve aumento da massa vegetal e algumas áreas de pastagens foram sendo ocupadas por atividades agrícolas no período de 2000 a 2018.

Palavras-chave: Morfometria; Geoprocessamento; Processamento Digital de Imagens; Bacia Hidrográfica do Córrego Ceroula; Brasil.

\section{ABSTRACT}

The hydrographic basin is the main physiographic unit of the terrain, considered as the ideal area for the planning and management of natural resources and production processes. This work aims to analyze the parametric of the terrain and land use and the vegetation cover of the watershed of the Ceroula stream (BHCC). The methodology was based on the use of remote sensing products that allowed soil and land use analysis and plant cover in geoprocessing software. The forms of relief and natural dynamics contributed to the configuration of land use and vegetation cover that are consolidated up to the present day, 
there was a slight increase in plant mass and some areas of pasture were being occupied by agricultural activities in Period from 2000 to 2008.

Keywords: Morphometry; Geoprocessing; Digital Image Processing; Hydrographic Basin of the Ceroula Stream; Brazil.

\section{Introdução}

Historicamente o processo de formação territorial do Estado de Mato Grosso do Sul (Brasil) foi marcado pela expansão das fronteiras agrícolas, com o objetivo estratégico de ocupação do cerrado, a fim de diversificar a economia nacional, observa (Barros \& Garcia, 2014).

O uso e ocupação da terra baseado na atividade agropastoril vem sendo fartamente citado na literatura científica como um dos causadores das problemáticas ambientais, sobretudo em áreas de cerrado, com vegetação e solo vulneráveis, conforme observa (Silva \& Lopes, 2018).

A paisagem é o conjunto dos elementos físicos, biológicos e sociais. O meio natural compreende a base para a sobrevivência do homem, constituindo-se como palco das relações humanas. Ao mencionar "palco das relações humanas", Barbosa (2011) faz uma menção às ações antrópicas de produção e consumo no espaço geográfico.

A análise de bacias hidrográficas pode ser incrementada com a utilização dos Sistemas de Informações Geográficas (SIGs), para aprimorar os processos de tomada de decisão que exigem informações espaciais (Barbosa \& Bacani, 2012; Beltrame, 1994) Desta forma são representadas no ambiente computacional as entidades reais do espaço geográfico (estradas, hidrografia, cobertura vegetal e os demais tipos de uso da terra)

Almeida, Santos, e Souza (2009) mencionaram que as geotecnologias envolvem a utilização de um conjunto de recursos computacionais e metodológicos, entre esses os SIGs e o Sensoriamento Remoto.

Seabra (2013) afirma que a análise do uso e cobertura da terra é indispensável para os estudos ambientais, pois retratam as pressões e impactos sobre os elementos naturais presentes na paisagem.

Neste sentido, o avanço da tecnologia computacional associado ao crescimento do volume de dados geográficos tem permitido investigar diversos fatores e elementos naturais. 
A área selecionada para o desenvolvimento desta pesquisa é a Bacia Hidrográfica do Córrego Ceroula (BHCC), parte dessa área está inserida na Área de Proteção Ambiental (APA) da Bacia do Córrego Ceroula (Campo Grande, 2001).

Mato Grosso do Sul (1990) e Quevedo, Stefanes, \& Paranhos Filho (2009), apontam que parte da bacia do Córrego Ceroula, existente no Município de Campo Grande enquadra-se como bacia a ser preservada para atender futura demanda do abastecimento público da cidade, porém, as análises de Menezes e Salgado (2018) identificaram que há áreas de degradação de solo em pontos localizados dentro dos limites territoriais da APA da Bacia do Córrego Ceroula, afetando as áreas de nascentes do córrego Ceroula. Outra constatação foi realizada por Lima, Farias, e Dualibi (2016), evidenciam que o Córrego Ceroula possui áreas suscetíveis a erosão dos solos.

Nesta perspetiva e a fim de contribuir com instrumentos metodológicos e resultados que apontam a situação ambiental da BHCC, o objetivo desta pesquisa é realizar uma avaliação paramétrica de terreno e o mapeamento do uso da terra e cobertura vegetal da BHCC por meio de dados de sensoriamento remoto e técnicas de geoprocessamento.

\section{Materiais e métodos}

\section{1. Área de estudo}

A Bacia Hidrográfica do Córrego Ceroula (BHCC) está localizada entre os paralelos $20^{\circ} 35^{\prime} 14,09^{\prime \prime S}$ e $20^{\circ} 02^{\prime} 31,04^{\prime \prime} \mathrm{S}$ e os Meridianos, $54^{\circ} 25^{\prime} 45,95^{\prime \prime} \mathrm{W}$ e $55^{\circ} 12^{\prime} 12,84^{\prime \prime} \mathrm{W}$ e possui uma área territorial de aproximadamente $1.271,85 \mathrm{Km}^{2}$, está a noroeste do município de Campo Grande, capital do Estado de Mato Grosso do Sul (Brasil) e em partes dos municípios de Jaraguari, Rochedo e Terenos, conforme a Figura 1.

A BHCC possui feições geomorfológicas pertencentes ao planalto dissecado da borda ocidental da bacia do Paraná e do planalto de Campo Grande (IBGE, 2018).

O arcabouço geológico está predominantemente estruturado no grupo São Bento, formação Serra Geral, do período cretáceo e se caracterizam por rochas basálticas intercaladas por arenitos, possuindo feições geológicas da formação Botucatu e uma pequena área pertencente ao grupo Caiuá I (IBGE, 2018). 


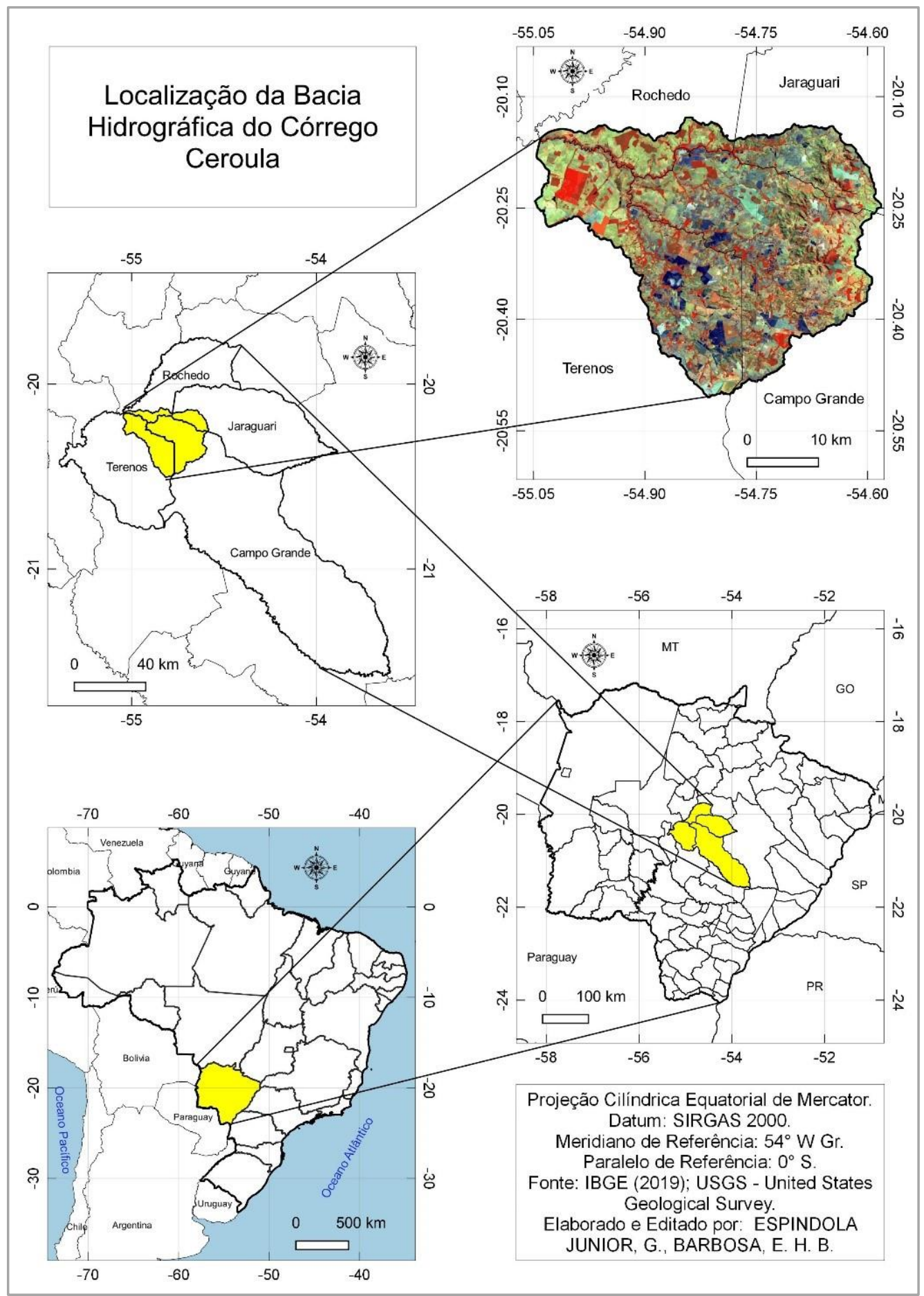

Figura 1 - Localização da Bacia Hidrográfica do Córrego Ceroula (BHCC).

Fonte: Elaboração própria com dados de IBGE (2019); USGS - United States Geological Survey.

Predomina na BHCC solos do tipo Latossolos Vermelho distróficos, bem desenvolvidos e profundos de textura argilosa a muito argilosa, e também existem pequenas porções de Neossolos Quartzarênico órtico e Neossolo Litólico eutrófico, com textura arenosa (IBGE, 2018). 
O clima na BHCC é úmido a subúmido com duas estações bem definidas, seco no inverno e chuvoso no verão, com pluviosidade anual de 1.200 a $1.500 \mathrm{~mm}$ nos municípios de Campo Grande e Jaraguari e de 1.500 a 1.750 mm em Rochedo e Terenos, ambos localizados no Estado de Mato Grosso do Sul (Seplan, 1990).

Segundo Silva, Pott, e Abdon (2011), a vegetação na BHCC é formada por remanescentes de vegetação ciliar aluvial, vegetação secundária, pastagem plantada, agricultura, áreas de influência urbana, áreas de reflorestamento e áreas degradadas por mineração.

O autor, aponta também, os fragmentos de savana florestada, savana arborizada, savana sem floresta de galeria, savana com floresta de galeria, savana florestada com áreas de savana arborizada, savana florestada com associação de floresta estacional decídua submontana, savana arborizada com associações de savana gramíneo lenhosa, para a composição da formação vegetal da BHCC.

A rede de drenagem da $\mathrm{BHCC}$ é de aproximadamente $210 \mathrm{~km}$ de canais fluviais e o principal curso d'água é o Córrego Ceroula com aproximadamente $80 \mathrm{Km}$ de extensão, as principais nascentes que formam os cursos d'água estão localizadas nos municípios de Campo Grande e Jaraguari, ambos no Estado de Mato Grosso do Sul.

\subsection{Materiais}

O referencial teórico-metodológico que subsidiou os procedimentos técnicos operacionais para o desenvolvimento dessa pesquisa fundamentou-se nas propostas de: Novais (2015), DeBiase (1992), Ross (1994), Mendonça (1999), Oliveira (2002), Valeriano (2008), Quevedo, et al. (2009) e Silva, Barbosa e Cunha (2016).

Para o desenvolvimento desta pesquisa foram utilizados os seguintes materiais:

- Base cartográfica digital do Brasil, na escala 1:250.000, atualização 2017, disponibilizada pelo Instituto Brasileiro de Geografia e Estatística (IBGE);

- Rede de drenagem, na escala 1:100.000, arquivo vetorial do projeto GeoMS (Silva et al., 2011);

- Imagem do radar SRTM (Shuttle Radar Topographic Mission), quadrícula 20S555, com resolução espacial de 30 metros. (Valeriano, 2008); 
- Imagem do satélite LANDSAT-5, sensor TM (Thematic Mapper), órbita 225, ponto 74, datada de 22/08/2000, composição colorida R4 G5 B3, disponibilizado pelo Instituto Nacional de Pesquisas Espaciais (INPE);

- Imagem do satélite LANDSAT-8, sensor OLI (Operational Land Imager), órbita 225, ponto 74, datada de 24/08/2018, composição colorida R5 G6 B4, disponibilizado pelo INPE.

O software utilizado para as análises de terreno e confecção dos produtos temáticos foi o Qgis 3.4.11 distribuído pela Open Source Geospatial Foundation (OSGeo), já para o Processamento Digital de Imagens (PDI) foi utilizado o Spring 5.5.5 distribuído pelo INPE.

\subsection{Métodos}

Inicialmente foi realizada a correção de depressões no Modelo Digital de Elevação (MDE) e a delimitação automática da área da bacia através do algoritmo fill sinks elaborado por Wang e Liu (2006), do software de análises hidrológicas System for Automated Geoscientific Analyses (SAGA).

Foram elaborados três produtos cartográficos tendo como base os dados SRTM/TOPODATA para subsidiar a avaliação paramétrica de terreno da bacia do córrego Ceroula, apoiado na proposta de (Barbosa \& Bacani, 2011):

Mapa hipsométrico, dividido em seis classes temáticas, de modo a auxiliar o entendimento da compartimentação geomorfológica e da dinâmica do uso da terra;

Mapa de declividade, apoiado na proposta de DeBiase (1992), que resultou na adoção de classes de declividade, foram definidas cinco classes, conforme proposto por Ross (1994); Mapa de orientação de vertentes que representa os diferentes graus azimutais de exposição das vertentes, onde foram adotadas quatro classes com variações de: $315^{\circ}$ a $45^{\circ}(\mathrm{N}), 45^{\circ}$ a $135^{\circ}(\mathrm{E}), 135^{\circ}$ a $225^{\circ}(\mathrm{S})$ e $225^{\circ}$ a $315^{\circ}(\mathrm{W})$, apoiado na proposta de Mendonça (1999).

O PDI foi dividido em 4 (quatro) etapas:

- Pré-processamento: nesta etapa as imagens foram corrigidas geometricamente para eliminar possíveis distorções advindas do processo de imageamento do satélite conforme afirma Crostá (como citado em Oliveira, 2002). As imagens foram georreferenciadas no Spring 5.5.5 utilizando pontos de controle obtidos a partir da 
imagem de referência do satélite LANDSAT-5 TM, datada de 09/11/1988. Posteriormente ao georreferenciamento, as imagens foram submetidas a uma análise comparativa de uma sobre a outra, por meio da ferramenta acoplar;

- Técnicas de realce: Foi executado um contraste linear com base no histograma da imagem, utilizando o cursor para ajustar os níveis de cinza, conforme (Oliveira, 2002; Crostá, 1992) a expansão do histograma não altera as informações da imagem bruta, apenas possibilita uma melhor visualização dos alvos aos olhos do interprete;

- Segmentação: Adotou-se o limiar de similaridade 40 e área 38 pixels para a imagem LANDSAT-5 TM conforme proposto por (Silva et al., 2016) devido à grande quantidade de tonalidades (cores de pixels) e o limiar de similaridade 15 e área de 625 pixels para a imagem LANDSAT-8 OLI, conforme proposto por Quevedo et al. (2009).

- Classificação: foi utilizado o algoritmo Bhattacharya de classificação por regiões para a elaboração do mapeamento do uso da terra. Após a escolha do algoritmo foi realizada à etapa de treinamento em que são criadas as classes temáticas e colhidas amostras de cada tema. Com a definição do algoritmo de classificação e limiar de aceitação de 99,9\%, procedeu-se a definição de 7 (sete) classes temáticas. Agricultura; Áreas Úmidas; Pastagem; Silvicultura; Solo Nu; Urbano; e Vegetação Arbórea. Após o emprego do algoritmo de classificação supervisionada, o produto temático passou pelo processo de edição matricial.

- A partir dos elementos interpretativos, cor, textura, padrão e forma, foi elaborado a chave de interpretação (Tabela 1). 
Tabela 1 - Chave de interpretação para o mapeamento do uso e ocupação da terra e cobertura vegetal.

\begin{tabular}{|c|c|c|c|c|}
\hline \multirow{2}{*}{$\begin{array}{c}\text { Classes } \\
\text { Temáticas }\end{array}$} & \multicolumn{2}{|c|}{ Tonalidade } & \multirow{2}{*}{ Cor } & \multirow{2}{*}{ Textura/Forma } \\
\hline & 2000 & 2018 & & \\
\hline Agricultura & & & Azul/Ciano & $\begin{array}{c}\text { Média-Rugosa } \\
\text { Regulares/ } \\
\text { Irregulares }\end{array}$ \\
\hline Área Úmida & & & $\begin{array}{l}\text { Verde Musgo/ } \\
\text { Cinza Escuro }\end{array}$ & $\begin{array}{c}\text { Média-Rugosa/ } \\
\text { Irregulares }\end{array}$ \\
\hline $\begin{array}{c}\text { Área } \\
\text { Urbanizada }\end{array}$ & & & $\begin{array}{c}\text { Mistura de } \\
\text { Cores }\end{array}$ & Rugosa/Irregular \\
\hline Pecuária & & & $\begin{array}{c}\text { Verde/Amarelo } \\
\text { Claro }\end{array}$ & $\begin{array}{l}\text { Média-Rugosa/ } \\
\text { Regular-Irregular }\end{array}$ \\
\hline Solo Exposto & & & Branco & $\begin{array}{l}\text { Lisa Irregulares/ } \\
\text { Regulares }\end{array}$ \\
\hline $\begin{array}{c}\text { Vegetação } \\
\text { Nativa }\end{array}$ & & & $\begin{array}{l}\text { Vermelho } \\
\text { Escuro }\end{array}$ & $\begin{array}{c}\text { Rugosa/Irregulares } \\
\text { Lisa/Irregulares }\end{array}$ \\
\hline Silvicultura & $\begin{array}{c}\text { Não } \\
\text { Mapeado }\end{array}$ & & Vermelho & Lisa/Regulares \\
\hline
\end{tabular}

Fonte: Adaptado de Florenzano (2002) e (Silva et al., 2016). 
Após a coleta das amostras a imagem foi classificada utilizando o método da distância de Bhattacharya, conforme a Equação 1 (Jensen, 1996).

$B(p i, p j)=1 / 2(m 1+m 2)^{t} \sum(m i-m j)+1 / 2 \ln \frac{|\Sigma(m i-m j)|}{\left.|\Sigma i|^{1 / 2}\right|^{|\Sigma j|^{1 / 2}}}$

Onde:

- $\quad \mathrm{B}=$ distância de Bhattacharya;

- $\quad$ Pi e Pj = pixels nas classes i e j;

- $\quad$ mi e mj = médias das classes i e j;

- $\mathrm{T}=$ matriz transposta;

- $\quad$ In = logaritmo neperiano;

- $\quad$ i e j = classes dentro do contexto.

Para a análise estatística do desempenho do classificador foram coletadas 63 amostras das classes temáticas que foram submetidas ao indice Kappa de concordância (equação 2) e acurácia global (equação 3), os valores foram analisados conforme os limiares da (Tabela 2) estabelecidos por (Landis \& Koch, 1977).

De acordo com Colgaton (1991), o coeficiente Kappa (K) é satisfatório na avaliação da precisão de uma classificação temática por levar em consideração toda a matriz de confusão no seu cálculo inclusive os elementos de fora da diagonal principal, os quais representam as discordâncias na classificação.

$$
\hat{K}=\frac{N \sum_{i=1}^{k} x_{i i}-\sum_{i=1}^{k}\left(x_{i+} \cdot x_{+i}\right)}{N^{2}-\sum_{i=1}^{k}\left(x_{i+} \cdot x_{+i}\right)}
$$

2

$$
\text { Acurácia }_{\text {global }}=\left(\frac{\sum_{i=1}^{k} x_{i i}}{N}\right)
$$

Onde:

- $\hat{K}$ : valor estimado Kappa;

- $k$ : número de linhas;

- $x_{i i}$ : número de observações na linha $i$ e coluna $i ;$

- $\quad \sum_{i=1}^{k} x_{i i}$ : soma dos elementos da matriz em sua diagonal principal; 
- $x_{i+}$ : soma total das observações para as linhas;

- $x_{+i}$ : soma total das observações para as colunas;

- $\quad \mathrm{N}$ : número de observações total.

Tabela 2 - Índice kappa de qualidade da classificação.

\begin{tabular}{c|c}
\hline Índice Kappa & Concordância \\
\hline 0 & Péssima \\
0,01 a 0,20 & Ruim \\
0,21 a 0,40 & Razoável \\
0,41 a 0,60 & Boa \\
0,61 a 0,80 & Muito Boa \\
0,81 a 1,00 & Excelente \\
\hline
\end{tabular}

Fonte:Traduzido de Landis e Koch (1977).

Assim sendo, aplicaram-se aos produtos, técnicas de tratamento digital de imagens orbitais, conforme procedimento metodológico adotado por Silva et al. (2016) para gerar o mapa de uso da terra e cobertura vegetal.

\section{Resultados e discussões}

Para a avaliação paramétrica de terreno foram elaborados os seguintes produtos cartográficos: Hipsometria, Declividade e Orientação das vertentes (Figura 2).

As classes hipsométricas (Tabela 3) mostram que do alto ao médio curso as altitudes variam de 720 a 370 metros de altitude. Essas terras são formadas por áreas úmidas e remanescentes de matas. Observa-se que do médio ao baixo curso da bacia, as altitudes variam de 370 a 225 metros, com predomínio de áreas de atividades agropastoris e fragmentos de matas. 


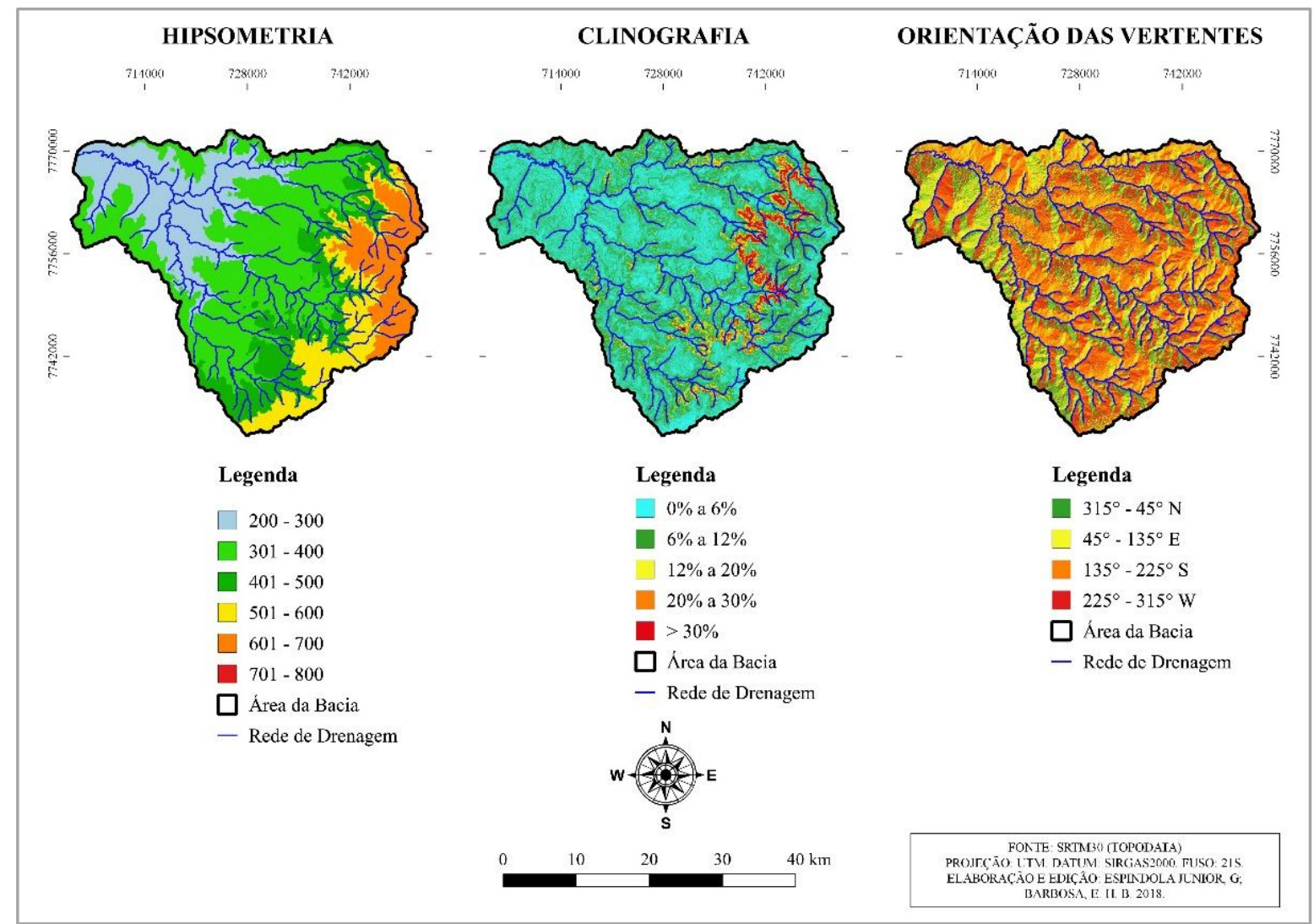

Figura 2 - Avaliação paramétrica de terreno da Bacia do Córrego Ceroula.

Fonte: Elaboração própria com dados de SRTM

Tabela 3 - Classes hipsométricas.

\begin{tabular}{c|c|c}
\hline Classes hipsométricas $(\mathbf{m})$ & Área $\left(\mathbf{k m}^{\mathbf{2}}\right)$ & Área (\%) \\
\hline $\mathbf{2 0 0 - 3 0 0}$ & 287,85 & 22,63 \\
$\mathbf{3 0 1 - 4 0 0}$ & 520,12 & 40,89 \\
$\mathbf{4 0 1 - 5 0 0}$ & 189,51 & 14,90 \\
$\mathbf{5 0 1 - 6 0 0}$ & 142,85 & 11,23 \\
$\mathbf{6 0 1 - 7 0 0}$ & 129,66 & 10,19 \\
$\mathbf{7 0 1 - 8 0 0}$ & 1,81 & 0,16 \\
\hline
\end{tabular}

Fonte: Elaboração própria

As classes de declividade (Tabela 4) foram fatiadas conforme a proposta de Ross (1994) e indicam que nos topos de morro do alto curso da bacia os declives são de médio a muito forte e correspondem a aproximadamente $10 \%$ da área da bacia, no médio ao baixo curso variam de fraca a muito fraca e correspondem a mais de $90 \%$ da área da bacia. 
Tabela 4 - Classes de declividade.

\begin{tabular}{c|c|c}
\hline Classes de declividade (\%) & Área $\left(\mathbf{k m}^{\mathbf{2}}\right)$ & Área (\%) \\
\hline De $\mathbf{0}$ a 6 (Muito Fraca) & 794,11 & 61,83 \\
De $\mathbf{6}$ a $\mathbf{2}$ (Fraca) & 364,54 & 28,39 \\
De $\mathbf{1 2}$ a $\mathbf{2 0}$ (Média) & 68,41 & 5,33 \\
De $\mathbf{2 0}$ a $\mathbf{3 0}$ (Forte) & 27,16 & 2,12 \\
$>\mathbf{3 0}$ (Muito Forte) & 29,92 & 2,33 \\
\hline
\end{tabular}

Fonte: Adaptado de Ross (1994)

A orientação das vertentes (Tabela 5) mostra que predomina na bacia as vertentes com maior radiação solar no período da tarde estão orientadas para oeste - norte e correspondem a aproximadamente $54 \%$ da área e as vertentes orientadas para leste - sul, que correspondem a aproximadamente $46 \%$, de acordo com Neves (2011) essas vertentes recebem uma maior radiação solar no período da manhã o que determina um maior conforto térmico, são áreas que possibilitam a implementação de projetos de recuperação da vegetação. Sendo assim mapeamentos de orientação de vertentes são importantes instrumentos para apoiar ocupações futuras, e como produtos para subsidiar práticas de recuperação ambiental conforme (Vick, Silva, \& Bacani, 2018).

Tabela 5 - Classes da orientação das vertentes.

\begin{tabular}{c|c|c}
\hline Grau azimutal de orientação das vertentes & Área $\left(\mathbf{k m}^{\mathbf{2}}\right)$ & Área (\%) \\
\hline $315^{\circ}-\mathbf{4 5}^{\circ} \mathrm{N}$ & 295,74 & 23,02 \\
$\mathbf{4 5}^{\circ}-135^{\circ} \mathrm{E}$ & 227,65 & 17,72 \\
$\mathbf{1 3 5}^{\circ}-\mathbf{2 2 5 ^ { \circ } \mathrm { S }}$ & 367,89 & 28,64 \\
$225^{\circ}-\mathbf{3 1 5 ^ { \circ } \mathrm { W }}$ & 392,72 & 30,58 \\
\hline
\end{tabular}

Fonte: Elaboração própria

Observada as particularidades morfológicas da BHCC, foi realizado o mapeamento do uso da terra e cobertura vegetal, para os anos de 2000 e 2018 conforme a Figura 3. 


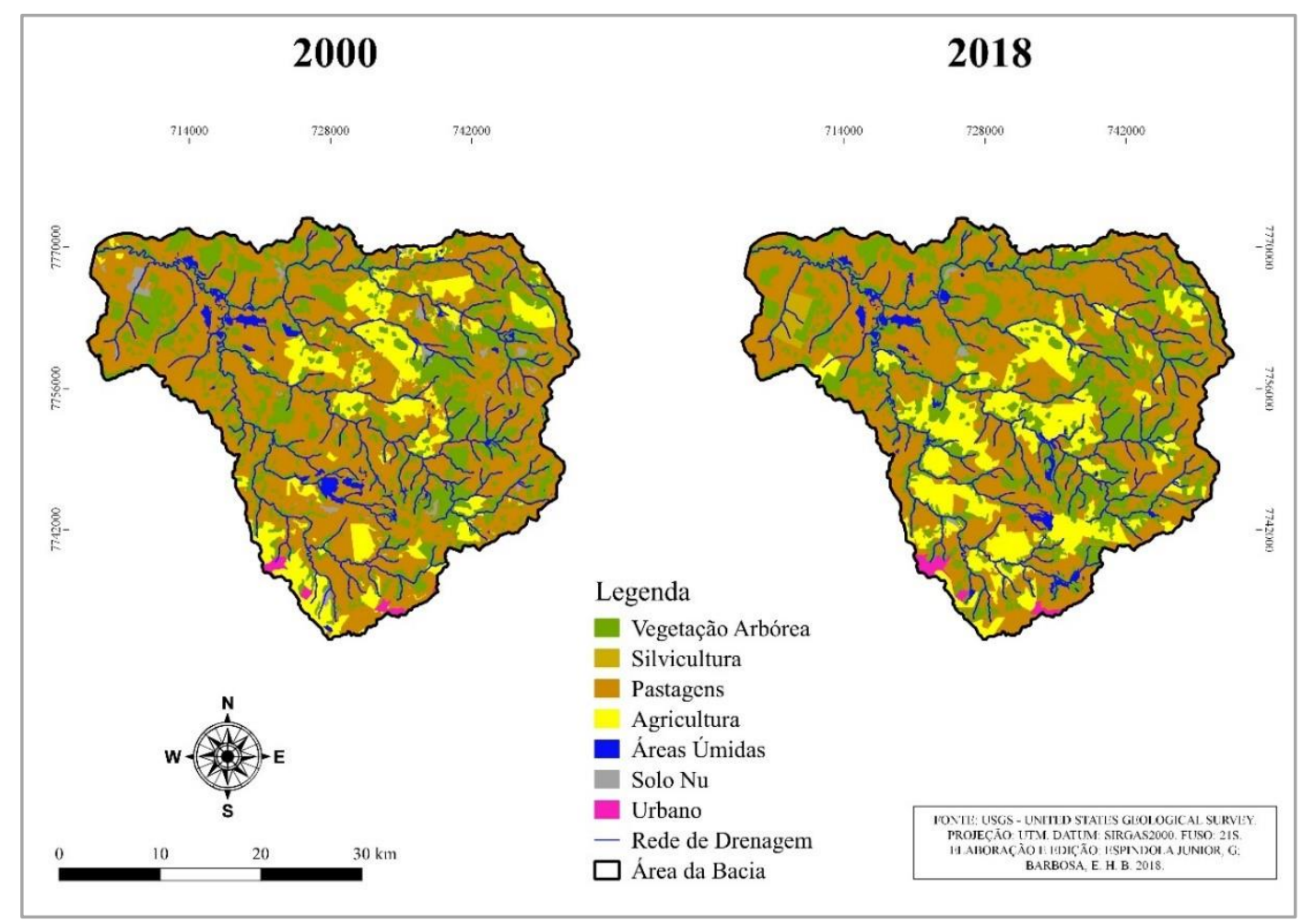

Figura 3 - Mapeamento do uso da terra e cobertura vegetal.

Fonte: Elaboração própria com dados de USGS

Ao observar o quantitativo de áreas (Tabela 6), é nítido que houve um leve aumento de área no período apresentada pela classe Agricultura. Assim, a classe passou de $162,44 \mathrm{~km}^{2} \mathrm{em}$ 2000 para 220,61 $\mathrm{Km}^{2}$ em 2018, ou seja, em 2000 essas áreas correspondiam a 12,78\% da área total da BHCC, enquanto que em 2018 as áreas correspondem a 17,34\% do total.

Quevedo et al. (2009), apontaram que a atividade agrícola em 1985, correspondia à 5,46\% da área total da bacia, porém em 2007, este percentual aumentou 0,16\%. Ao comparar com os resultados obtidos em 2000, o acréscimo foi de 7,32\% entre os anos de 1985 e 2000.

As áreas úmidas mapeadas no período equivalem a cerca de $37,09 \mathrm{~km}^{2}$ no ano de 2000 e de $31,72 \mathrm{~km}^{2}$ em 2018 , ou seja, 2,49\% da área total da BHCC.

As áreas de pastagens são totalidade na BHCC, em 2000 correspondiam a 766,30 Km², ou seja $60,26 \%$ da bacia, em 2018 correspondem a 673,12km², ou seja, 52,92\% da área total, uma perda de área de $93,18 \mathrm{~km}^{2}$ frente a leve expansão da agricultura no período analisado. Para o período de 1985 a 2007, Quevedo et al. (2009), afirmaram que este tipo de cobertura aumentou praticamente $11 \%$, comparada à área total da bacia. 
As áreas de solo nu correspondiam a $18,38 \mathrm{~km}^{2}$ em 2000 e tiveram redução para $4,20 \mathrm{Km}^{2}$.

As áreas urbanas que em 2000 eram de $5,64 \mathrm{~km}^{2}$ passaram para $8,01 \mathrm{~km}^{2}$ em 2018, conforme a grade estatística do censo 2010 a população urbana que tem seus domicílios dentro da BHCC é de 13.358 pessoas entre ambos os sexos (IBGE, 2016).

Os remanescentes de vegetação correspondiam a $281,59 \mathrm{~km}^{2}$ no ano de 2000 , ou seja, 21,83\% da área total da BHCC, e no período de 18 anos passaram para $322,06 \mathrm{~km}^{2}$, ou seja, $25,32 \%$ da área total.

Tabela 6 - Quantitativo das classes do uso da terra e cobertura vegetal 2000 e 2018.

\begin{tabular}{c|c|c|c|c}
\hline \multirow{2}{*}{ Classes Temáticas } & \multicolumn{2}{|c|}{ Área em 2000} & \multicolumn{2}{c}{ Área em 2018 } \\
\cline { 2 - 5 } & $\left(\mathrm{km}^{2}\right)$ & $(\%)$ & $\left(\mathrm{km}^{2}\right)$ & $(\%)$ \\
\hline Agricultura & 162,44 & 12,78 & 220,61 & 17,34 \\
Áreas Úmidas & 37,09 & 2,92 & 31,72 & 2,49 \\
Pastagem & 766,30 & 60,26 & 673,12 & 52,92 \\
Silvicultura & - & - & 12,13 & 0,95 \\
Solo Nu & 18,38 & 1,45 & 4,20 & 0,36 \\
Urbano & 5,64 & 0,44 & 8,01 & 0,62 \\
Vegetação Arbórea & 281,59 & 22,15 & 322,06 & 25,32 \\
\hline
\end{tabular}

Fonte: Elaboração própria

Foram coletadas 63 amostras a campo e os resultados da análise estatística do desempenho do classificador validam o mapeamento do uso e ocupação qualificando como excelente, apresentando os valores de 0,82 para o índice kappa e 0,87 para a acurácia global, conforme os limiares estabelecidos por (Landis \& Koch 1977).

Os estudos analisados apontam que a relação perda da Vegetação Arbórea significa aumento da Pastagem (Lima et al., 2016; Quevedo et al., 2009). Porém, pela análise multitemporal do uso da terra e cobertura vegetal, para os anos 2000 e 2018, percebe-se 
uma redução acentuada de 7,34\% da classe temática pastagem, em contrapartida, há um aumento de 4,56\% da classe Agricultura e a presença de 0,95\% da classe Silvicultura.

\section{Conclusão}

A avaliação paramétrica mostrou-se como um importante instrumento para a análise das formas de relevo correlacionadas com os tipos de uso e ocupação da terra na bacia hidrográfica, o relevo plano de declividade fraca a muito fraca que abrange mais de $90 \%$ da área da BHCC, os solos bem desenvolvidos e bem drenados, assim como o clima úmido a semiúmido bem definido e com boa quantidade de precipitação anual são fatores que contribuíram para a configuração territorial predominante, baseada na agricultura e em áreas de pastagens.

As ferramentas e técnicas de geoprocessamento se mostraram eficazes na análise preliminar dos aspectos físicos da bacia do Córrego Ceroula, após uma busca por estudos científicos que versam sobre a área de estudo nota-se que pouco material foi produzido, neste sentido esta avaliação visa auxiliar nos possíveis estudos de avaliação e zoneamento ambiental na área.

Os estudos evidenciam que as principais causas de impactos ambientais estão correlacionados ao uso da terra para agricultura e pastagem, isso acelera os processos erosivos e o assoreamento dos cursos hídricos, como também pode vir a poluir esses mananciais de água, sabe-se também que essas atividades são de fundamental importância para o desenvolvimento econômico regional e local, e não podem ser interrompidas de uma hora para outra.

Portanto cabe observar de que forma esses usos estão sendo feitos, para que os impactos ao meio ambiente sejam mitigados, pois as atividades agropastoris são a principal matriz econômica da BHCC, sendo assim recomenda-se a utilização dos estudos territoriais já elaborados para o Estado de Mato Grosso do Sul para a elaboração de planos de manejo sustentáveis na BHCC pois a mesma possui em sua extensão territorial partes ou totalidades de 4 (quatro) Áreas de Proteção Ambiental e 1 (um) Monumento Natural que totalizam uma área de $888,26 \mathrm{Km}^{2}$, ou seja, $69,83 \%$ da bacia são Unidades de Conservação. 


\section{Referências}

Almeida, A. Q. de., Santos, A. R. dos., Souza, C. A. M. de., \& Tulli, L. M. A. (2009). Uso de técnicas de sensoriamento remoto na análise multitemporal do desmatamento ocorrido na microbacia do Córrego do Galo, Domingos Martins, ES. Revista Científica eletrônica de engenharia florestal, 7 (14), 74-88

Barbosa, E. H. B., \& Bacani, V. M. (2011). Avaliação paramétrica de terreno e o uso da terra e cobertura vegetal da Bacia do Córrego João Dias, Aquidauana - MS. In: Anais XV Simpósio Brasileiro de Sensoriamento Remoto SBSR, 1208-1215

Barbosa, E. H. B., \& Bacani, V. M. (2012). Análise da fragilidade ambiental da bacia do Córrego João Dias, Aquidauana - MS, Geografia (Londrina), 21 (2). 23-43. doi: 10.5433/2447-1747.2012v21n2p23

Barros, E. C. D. R. de., \& Garcia, E. M. G. (2014). Gestão Ambiental em mato Grosso do Sul: Conceitos e práticas. Instituto de Meio Ambiente de Mato Grosso do Sul, Campo Grande, MS (ISBN: 978-85-99880-70-8). Disponível em: http://www.servicos.ms.gov.br/imasuldownloads

Beltrame, A. da V. (1994). Diagnóstico do meio físico de bacias hidrográficas: Modelo e aplicação. Florianópolis, Santa Catarina, Brasil: UFSC

Campo Grande. (2001). Decreto Municipal n. 8.264/2001 - Cria a Área de Proteção Ambiental da Bacia do Córrego Ceroula - APA do Ceroula - localizada no município de Campo Grande-MS, e dá outras providências. Disponivel em: http://www.campogrande.ms.gov.br/semadur/downloads/decreto-municipal-n-8-264-de-27de-julho-de-2001/

Colgaton, R. G. (1991). A review of assessing the accuracy of classifications of remotely sensed data. Remote Sensing of Environment, 49 (12), 1671-1678. doi: 10.1016/0034-4257(91)90048-B

DeBiase, M. (1992). A Carta Clinográfica. Os métodos de representação e elaboração. Revista do Departamento de Geografia, 6, 45-60. doi: 10.7154/RDG.1992.0006.0004

Florenzano, T. G. (2002). Imagens de satélite para estudos ambientais. São Paulo, Brasil: Oficina de Textos

IBGE. (2010). Grade Estatística. Disponível em: https://www.ibge.gov.br/geociencias/downloadsgeociencias.html

IBGE. (2017). Base cartográfica do Brasil Escala 1:250.000. Disponível em: https://downloads.ibge.gov.br/downloads_geociencias.htm

IBGE. (2018). Mapeamento de recurso naturais do Brasil Folha SF-21- Campo Grande Escala 1:250.000. Disponível em: <https://downloads.ibge.gov.br/downloads_geociencias.htm

Jensen, J. R. (2009). Sensoriamento Remoto do Ambiente: Uma Perspectiva em Recursos Terrestres. São José dos Campos, São Paulo, Brasil: Parêntese

Landis, J.R., \& Koch, G.G. The measurement of observer agreement for categorical data. Biometrics, 33 (1), 159-174. doi: $10.2307 / 2529310$

Lima, J. A. M., Farias, E. F., Duailibi, K. C. M., Magalhães Filho, F. J. C., \& Cavalheri, P. S. (2016). Influência do Uso e Ocupação do Solo na Qualidade da Água para Consumo Humano. In: Anais do X Simpósio Internacional de Qualidade Ambiental, 1-8

Mendonça, F. (1999). Diagnóstico e análise ambiental de microbacia hidrográfica: Proposição metodológica na perspectiva do zoneamento, planejamento e gestão ambiental, RA'EGA (3). doi: 10.5380/raega.v3i0.18225

Menezes, C. R., \& Salgado, C. M. (2018). Uso do Solo e aspectos da paisagem da Bacia Hidrográfica do Angico, na Área de Proteção Ambiental do Ceroula - Campo Grande/MS. Formação, 25 (44), 261-277. doe: 10.33081/formacao.v25i44.4418

Neves, L. P. (2011). Adoção do Partido na Arquitetura. Salvador, Bahia, Brasil: UDUFBA

Novais, M. P. S. (2015). Análise espacial de bacias hidrográficas a partir de SIG: um estudo da bacia hidrográfica do Itapicuru - Bahia. In: Anais do XVII Simpósio Brasileiro de Sensoriamento Remoto, 2719-2726 
Oliveira, J. C. (2002). Índice para avaliação de segmentação (IAVAS): uma aplicação em agricultura. 160p. Dissertação (Mestrado em Sensoriamento Remoto). Disponível em: https://www.researchgate.net/publication/266216779/download

Quevedo, E. R. de, Stefanes, M., Paranhos Filho, A. C., Quevedo, J. R. de, \& Copatti, A. (2009). Aplicação da segmentação (SPRING) de imagens para avaliação ambiental multitemporal da bacia do Córrego Ceroula - MS, no período 1985 -2007. In: Anais do XIV Simpósio Brasileiro de Sensoriamento Remoto (pp. 1481-1488)

Ross, J. L. S. (1994). Análise empírica da fragilidade dos ambientes naturais e antropizados. Revista do Departamento de Geografia, (8), 63-74. doi: 10.7154/RDG.1994.0008.0006

Seabra, V. da S. (2013). Análise espacial e multitemporal do padrão de fragmentação florestal na bacia hidrográfica do rio São João. In: Anais do XVI Simpósio Brasileiro de Sensoriamento Remoto, 7762-7769

SEPLAN. (1990). Atlas multirreferencial. (GE00019513-4). Campo Grande, Mato Grosso do Sul, Brasil: Secretaria de Planejamento e Coordenação Geral

Silva, J. S. V. da, Pott, A, Abdon, M. M, \& Santos, K. R. (2011). Projeto GeoMS: Cobertura vegetal e uso da terra do Estado de Mato Grosso do Sul. Campinas, São Paulo, Brasil: EMBRAPA

Silva, L. F. da, Barbosa, E. H. B., Cunha, E. R., \& Bacani, V. M. (2016). Monitoramento temporal de áreas de preservação permanente em uma área de proteção ambiental. Geofronter, 2 (1), 16-31

Silva, L. F. da; Barbosa, E. H. B.; Nogueira, B. M., \& Bacani V. M. (2011). Análise do desempenho de classificadores semi-automáticos na detecção de mudanças do uso da terra e cobertura vegetal nos municípios de Aquidauana e Anastácio-MS. In: Anais do XV Simpósio Brasileiro de Sensoriamento Remoto, 6666-6673

Valeriano, M. M. (2008). TOPODATA: Guia para a utilização de dados geomorfológicos locais. Disponível em: http://mtc-m16c.sid.inpe.br/col/sid.inpe.br/mtc-m18@80/2008/07.11.19.24/doc/publicacao.pdf

Vick, E. P., Silva, L. C. N., \& Bacani, V. M. (2017). Análise paramétrica da bacia hidrográfica do rio Pântano - MS. Associação dos Geógrafos Brasileiros - AGB, Três Lagoas, (26), 87-100

Wang, L., \& LIU, H. (2006). An efficient method for identifying and filling surface depressions in digital elevation models for hydrologic analysis and modelling. International Journal of Geographical Information Science, 20 (2), 193-213. doi: 10.1080/13658810500433453 